\title{
Phyto-oestrogens: a potential role in the prevention of CHD?
}

\author{
Aedin Cassidy and Bruce Griffin \\ Centre for Nutrition and Food Safety, University of Surrey, Guildford GU2 5XH, UK
}

\begin{abstract}
CHD is a major cause of morbidity and mortality in women. The incidence of CHD in premenopausal women is low but increases substantially after the menopause, and this difference suggests that endogenous oestrogens are cardioprotective. Observational prospective studies have consistently shown that exogenous oestrogens also lower CHD risk. The biological mechanisms by which endogenous and exogenous oestrogens exert their protective effect are multifactorial, affecting lipids, carbohydrate metabolism, body fat distribution and blood pressure. The prevention of CHD with oestrogen therapy is therefore aimed both at correction of the traditional risk factors and at direct control of vessel structure and function. The wide international variation in rates of CHD together with the lower mortality in sub-groups of the population suggests that a considerable proportion of CHD may be prevented by dietary modification. Since phytooestrogens are structually similar to oestrogen, they have the potential to mimic its effects in vivo. The hypocholesterolaemic effects of soyabean protein (rich in phyto-oestrogen precursors) are well established, but the underlying mechanism and atherogenic potential of these changes are unknown. One isoflavone, genistein, has been shown in vitro to exert effects which may slow the development of atherosclerotic disease. However, further studies are required to determine the dose-related changes induced by phyto-oestrogens on serum lipoproteins, haemostasis and vascular function.
\end{abstract}

Phyto-oestrogens: Oestrogens: Lignans: Soyabean: CHD

At any given age death rates in the UK for CHD in women are equivalent to the rates observed in men 10 years younger. Nevertheless, CHD is still a major cause of morbidity and mortality in women, and accounts for $23 \%$ of female mortality (Williams, 1997). Women appear to be protected from CHD in the premenopausal years and this pre- $v$. post-menopausal difference in CHD risk suggests a protective role for endogenous oestrogens. Evidence for the influence of oestrogens on CHD risk factors is derived from two principal sources: (1) from changes in lipoprotein metabolism and other risk variables on progression to the menopause; (2) from the impact of oestrogen administration. Since lifelong use of exogenous oestrogen is required for cardioprotection (Grodstein et al. 1996), the long-term risk-benefit balance is crucial. Cross-cultural trends in the incidence rate of CHD, and the lower mortality observed in vegetarians (Key et al. 1996), suggest that a considerable proportion of CHD may be preventable through diet. Large-scale epidemiological studies have highlighted the potential benefits of increased fruit and vegetable intake, specifically in relation to antioxidant nutrients and phenolic flavonoids (Hertog et al. 1993; Gaziano et al. 1995; Pandey et al. 1995). Plant foods also contain nonsteroidal phyto-oestrogens, and these weakly oestrogenic compounds may harbour considerable potential to act as oestrogen agonists in vivo and may play a vital role in the prevention of CHD (Setchell et al. 1984) by mimicking the actions of endogenous oestrogen.

\section{Effect of menopause on risk factors}

After the menopause, the increase in risk for CHD is promoted by a number of metabolic and vascular changes which may, in part, be related to oestrogen deficiency. The results of the Renfrew and Paisley prospective study suggest that women are relatively resistant to the adverse effects of the established risk factors for CHD (Isles et al. 1992). Despite a higher prevalence of raised total cholesterol, hypertension and obesity, the attributed risks for these factors are considerably lower for females than males in the UK. There is now evidence to suggest that metabolic abnormalities in risk factors may be more important in

\footnotetext{
Abbreviations: ER, oestrogen receptor; HRT, hormone-replacement therapy; Lp(a), lipoprotein (a); TAG, triacylglycerols. *Corresponding author: Dr Aedin Cassidy, fax +44 (0)1483 259341, email a.cassidy@surrey.ac.uk
} 
distinguishing risk in women than the more traditional risk factors that have been derived from studies on men (Williams, 1997). Alterations in serum lipoproteins become evident at the beginning of the menopause, with a progressive increase in total cholesterol and LDL-cholesterol levels. The effects on HDL-cholesterol levels are controversial, but more recent studies suggest that levels do not change significantly as a consequence of the menopause (Stevenson et al. 1993; Bergmann et al. 1997). This lack of an effect of the menopause on HDL-cholesterol may help to explain why the protective effects of oestrogen extend for sometime beyond the menopause. Some but not all studies have found serum oestradiol levels to be positively associated with HDL-cholesterol levels in post-menopausal women (Kuller et al. 1990). The menopause is also accompanied by an increase in serum triacylglycerol (TAG) levels of 7-35\%, independent of age. A recent meta-analysis of seventeen prospective studies identified serum TAG as an independent predictor of CHD risk in women (Hokanson \& Austin, 1996). However, although TAG levels increase after the menopause, they do not reach levels found in older men, but are generally closer to levels observed in young normolipidaemic men (Cohn et al. 1988).

Raised serum lipoprotein (a) ( $\operatorname{lp}(a)$; a close structural relative of $L D L$ ) has been shown to be an independent risk factor for CHD. Although the prevailing view has been that $L p$ (a) levels are unaffected by age and gender (levels are primarily genetically determined), more recently Bruschi et al. (1996) demonstrated that surgical menopause causes a sharp rise in plasma $L p(a)$ levels, with levels returning to baseline values with oestrogen treatment. Given that diets and most conventional drugs have no effect on $L p(a)$, the ability of oestrogen to decrease the concentration of this lipoprotein by up to $35 \%$ (Shewmon et al. 1994) is quite unique. The significant positive association between $\mathrm{Lp}$ (a) and follicle-stimulating hormone levels proves that changes in the former are strictly dependent on the hypooestrogenic state induced by oophorectomy, and thus suggest an important role for oestrogens in modulating Lp(a) levels.

The predominance of small dense LDL-cholesterol is emerging as a major determinant of LDL atherogenicity (see Griffin, 1999). After the menopause, dense LDL-cholesterol particles are present with increasing frequency (Campos et al. 1988). Since the density of LDL-cholesterol particles is related to TAG content, this may in part explain why plasma TAG have been found to be an independent risk factor for CHD in older post-menopausal women (Castelli, 1986) but not in younger women (Austin, 1988). Increased TAG may therefore be a marker for increased levels of atherogenic lipoproteins rather than the cause of the increased risk of CHD.

Multiple regression analysis indicates that between 25 and $50 \%$ of the reduction in cardiovascular events in postmenopausal oestrogen users is attributed to effects on lipoprotein metabolism (Soma et al. 1997). An additional contribution to risk may arise from the menopause producing unfavourable changes in haemostatic factors, with reports of increases in fibrinogen and factor VII and plasminogen activator inhibitor 1 , all of which would tend towards a prothrombotic state (Matthews et al. 1989;
Meilahn et al. 1990). Although fibrinogen may be a predictor of CHD in women, results from the Postmenopausal Estrogen/Progestogen Intervention trial suggest that it may not be an independent risk factor, since levels are independently related to other lifestyle and physical characteristics, including age, obesity, HDL, LDL (Stefanick et al. 1995).

Dysfunction of the arterial endothelium may also underlie the increased risk of CHD observed in post-menopausal women. Endogenous and exogenous oestrogens may exert their cardioprotective effects by direct effects on the vasculature, increasing cardiac output, arterial blood flow velocity and decreasing vascular resistance, and systolic and diastolic blood pressure (Magness \& Rosenfield, 1989; Farhat et al. 1996). At physiological concentrations, oestrogen decreased arterial smooth muscle cell migration and proliferation induced by endothelium injury in a mouse carotid artery model (Sullivan et al. 1995). Oestrogens have also been shown to exert acute and positive effects on the regulation of the arterial vasoreactivity in ovariectomized rhesus monkeys (Macaca mulatta; Williams et al. 1992). These direct effects of oestrogen on the arterial wall are thought to be mediated, at least in part, through classic steroid hormone receptors, the presence of which in premenopausal women has been demonstrated in vascular smooth muscle as well as endothelial cells of coronary arteries (Losordo et al. 1994; Kim-Schulze et al. 1996). However, to date little is known about the expression, function and distribution of oestrogen receptors (ER) in cardiovascular tissues and organs after the menopause.

\section{Hormone-replacement therapy}

The prevention of CHD with oestrogens is aimed both at correction of the traditional set of cardiovascular risk factors and at the direct control of vessel structure and function. Observational prospective studies have consistently shown that exogenous oestrogen therapy lowers risk for CHD (Stampfer et al. 1991; Meade \& Berra, 1992). Over thirty observational studies and thirteen case-control studies have examined the effect of hormone-replacement therapy (HRT) on cardiovascular events, and a recent meta-analysis estimated that the reduction in CHD associated with oestrogen is $44 \%$ (Stampfer \& Colditz, 1991). Part of this reduced risk in HRT users may be explained by selection bias, since women taking post-menopausal oestrogens tend to be healthier and of higher socio-economic status and, therefore, may have different lifestyles from non-users (BarrettConnor, 1991).

However, oestrogens clearly do have powerful biological actions that could explain their associated cardioprotective effects (Gerhard \& Ganz, 1995). The most important effects of HRT on lipoprotein metabolism relate to the decrease in LDL and increase in HDL, both by approximately $15 \%$ (Knopp, 1991). Although this does not explain all the cardioprotective effect of HRT, at present there is no consensus regarding the relative importance of other biochemical indices, although HRT appears to reverse the effect of the menopause on clotting factors (factor VII, plasminogen-activating factor 1 and fibrinogen) and $L p(a)$ levels, and have favourable effects on LDL subtypes (Soma et al. 1997). Paradoxically, HRT has been associated with 
increases in TAG of approximately $25 \%$ (Knopp, 1991). However, an oestrogen-induced reduction in LDL and reciprocal rise in HDL are likely to oppose the metabolic effects of elevated TAG (see Griffin, 1999), and thus outweigh the risk associated with the latter (Williams, 1997).

The observed cardioprotective effects of oestrogen appear to be related to current use and diminish after cessation of treatment (Grodstein et al. 1996). Postmenopausal women are therefore faced with a dilemma; oestrogen use may protect against CHD and osteoporosis but may increase the risks of breast and endometrial cancer (Colditz et al. 1995; Col et al. 1997). The risk of endometrial cancer is substantially mitigated by the addition of progestins (Beresford et al. 1997), which according to the 16-year follow-up of the Nurse's Health population study (Grodstein et al. 1996) do not appear to attenuate the cardioprotective effect of post-menopausal oestrogen therapy. Lingering concerns about the potential long-term risks associated with HRT preparations have stimulated interest in the manufacture of selective ER modulators, such as Raloxifene. These tissue selective agents could provide the benefits of oestrogen without the accompanying risk (Walsh et al. 1998). Raloxifene can produce oestrogen-agonistic effects in some factors (e.g. bone and cholesterol) and oestrogen-antagonistic effects in others (e.g. breast). In a recent randomized parallel-designed study Raloxifene favourably altered biochemical markers of CHD by decreasing LDL, fibrinogen and $\mathrm{Lp}(\mathrm{a})$ and increasing $\mathrm{HDL}_{2}$, without raising serum TAG concentrations (Walsh et al. 1998). In contrast to HRT, Raloxifene had no effect on HDL and plasminogen-activating factor 1 and a lesser effect on $\mathrm{HDL}_{2}$ and $L p(a)$, but for the most part the direction of the response paralleled that of HRT, although it was not necessarily of the same magnitude. The pattern of response bore a greater similarity to Tamoxifen (the anti-oestrogen drug successfully employed in breast-cancer treatment) than to HRT. This overall similarity between Raloxifene and Tamoxifen may be important, since the changes in risk factors induced by Tamoxifen may be responsible for the observed decrease in CHD mortality in women receiving Tamoxifen (McDonald \& Stewart, 1991).

In view of these studies, randomized trials are clearly required to define the effects of HRT (including different regimens and routes of administration) and other potential drug therapies on risk factors for $\mathrm{CHD}$, and importantly to determine the effects of treatment on clinical outcome. However, searching for an ideal drug therapy should not supersede the need to further investigate the potential importance of dietary modification, given the relatively unexplored potential of dietary phyto-oestrogens in the prevention of CHD. The nutritional importance of a highplant-based diet has already been recognized as potentially important in the prevention of many Western diseases, although the mechanism(s) by which dietary phytooestrogens may prevent CHD has to date not received adequate attention.

\section{Dietary phyto-oestrogens}

Phyto-oestrogens are naturally-occurring plant chemicals which are currently receiving considerable attention because<smiles>Oc1ccc2c(c1)CCC1C2CCC2C(O)CCC21</smiles><smiles>O=c1c(-c2ccc(O)cc2)coc2cc(O)ccc12</smiles>

Isoflavones

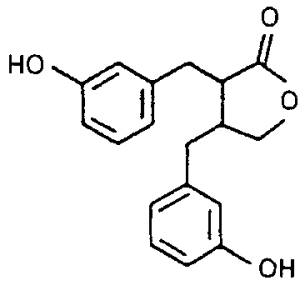

Lignans
Fig. 1. A structural comparison of oestrogens and phyto-oestrogens.

they offer potential alternative therapies for a range of hormone-dependent conditions, including cancer prevention, menopausal symptoms, CHD and osteoporosis. The two classes of phyto-oestrogens of particular interest to human health are the isoflavones, present in high concentrations in soyabean products, and the lignans, which are measurable in most fibre-rich foods, but linseed is currently the richest identified source (Setchell \& Adlercreutz, 1988). These compounds are strikingly similar in chemical composition to oestradiol (Fig. 1), bind to the ER (Shutt \& Cox 1972), and produce typical and predictable oestrogenic responses when administered to animals. Although these compounds have a much weaker binding affinity for the classic ER, ER $\alpha$, than oestradiol, when consumed in high concentrations these compounds have the potential to mimic the effects of exogenous oestrogens. Furthermore, the recent identification of the new ER, ER $\beta$ (Kuiper et al. 1996, 1997), may help to explain the mechanism of action of oestrogens on vascular tissues, since recent findings suggest that ER $\beta$ and not ER $\alpha$ may mediate some of the cardiovascular benefits of oestrogen (Iafrati et al. 1997). Phytooestrogens have significantly higher binding affinities for ER $\beta$ than ER $\alpha$, suggesting that this new ER may be important to the action of non-steroidal phyto-oestrogens (Kuiper et al. 1997).

Controlled intervention studies in premenopausal women provide direct evidence to suggest that diets containing phyto-oestrogens can produce oestrogenic effects in women of reproductive age (Cassidy et al. 1994, 1995). A daily intake of textured vegetable protein containing $45 \mathrm{mg}$ isoflavones modified characteristics of the menstrual cycle of healthy premenopausal women and suppressed the magnitude of the normal mid-cycle surge of folliclestimulating hormone and luteinizing hormone. This effect did not occur with an isoflavone-free soyabean protein, suggesting that the isoflavone fraction exerts this endocrine modifying effect, which occurs at the level of the hypothalamic pituitary-gonadal axis. Effects of soyabean diets on oestrogen-sensitive biochemical markers have also been demonstrated in post-menopausal women, and suggest that phyto-oestrogens can act as a weak oestrogen in 
postmenopausal women (Wilcox et al. 1990; Baird et al. 1995; Murkies et al. 1995; Cassidy et al. 1998). These compounds therefore have the potential to exert similar effects to those of HRT. This is supported by epidemiological evidence which suggests that the incidence of CHD is lower in Asian countries (where soyabean, a rich source of isoflavones, is a staple) than in Western countries (Lock et al. 1988). In addition, a lower mortality of CHD has been observed in vegetarians (Key et al. 1996), who would consume high levels of phyto-oestrogens, particularly lignans, as a result of their plant-based diet. However, although diets high in plant-based foods appear to protect from CHD, the mechanism for this protective effect and the active constituents present in plant foods have not been elucidated, and to date the antioxidant micronutrients and flavonoids have received most attention (Hertog et al. 1993; Gazioano et al. 1995; Pandey et al. 1995).

The hypocholesterolaemic effect of soyabean has been recognized from animal studies for almost 100 years (Carroll, 1991). Animal studies have shown that substituting soyabean protein for casein or other animal proteins causes a reduction in total cholesterol and LDL concentrations (Sirtori et al. 1993). However, in human subjects the clinical response to soyabean protein in terms of its effects on lipoprotein metabolism have been variable, partly because the effects are highly dependent on the initial serum cholesterol concentrations, but also because the studies conducted used different sources and doses of soyabean products and different study designs. A meta-analysis of thirty-eight intervention studies showed mean reductions in serum total cholesterol of $9.3 \%$, and $\mathrm{LDL}$ of $12.9 \%$ in response to soyabean protein (Anderson et al. 1995). This study concluded that an intake of $25 \mathrm{~g}$ soyabean protein/d would be associated with a $0.45 \mathrm{mmol} / \mathrm{l}$ decrease in serum cholesterol levels, and the hypocholesterolaemic effect of soyabean was most marked in subjects with the highest initial serum levels. The effect on HDL was marginal, with a small nonsignificant increase (Anderson et al. 1995). In addition, a recent cross-sectional study showed a significant inverse relationship between soyabean intake and total cholesterol level in a Japanese population (Nagata et al. 1998). In our own studies normocholesterolaemic premenopausal women showed a mean reduction of $9.6 \%$ in total cholesterol levels when $60 \mathrm{~g}$ soyabean protein was given daily over a 1-month period (Cassidy et al. 1994). Half this dose resulted in a significant decrease in TAG concentrations (Cassidy $e t$ al. 1995). No randomized cross-over trials have been conducted as yet to examine the effect of phyto-oestrogenrich diets on the spectrum of biochemical markers of lipoprotein metabolism and haemostatic factors in human subjects. However, the few short-term studies that have examined the effects of soyabean on lipoprotein metabolism in post-menopausal women and in men have shown no significant effect (Gooderham et al. 1996; Cassidy et al. 1998). Furthermore, results from studies using purified isoflavone supplements have not shown any effect on lipids (Nestel et al. 1997; Hogson et al. 1998), although this lack of effect could be explained by the absence of a food matrix, or by the absence of other components of soyabean which may interact with isoflavones to exert the hypocholesterolaemic effect. Quantitatively, the lignans are more important in relation to the UK diet than isoflavones, as they are present in measurable amounts in many plant foods that are regularly consumed in the normal diet (Cassidy, 1997). However, only limited information on their biological effects in human subjects is available. A short-term study in which $40 \mathrm{~g}$ linseed (the richest identified source of lignans) was fed showed favourable modifications to lipid profiles in postmenopausal women and elderly men (Cassidy et al. 1998). Since the cholesterol reduction appears to be most effective in hypercholesterolaemic subjects, further studies therefore need to be conducted in these sub-groups to examine the dose-response effects of phyto-oestrogen-rich foods on a wide range of biochemical markers of CHD risk. In particular, the relative importance of lignans needs to be addressed.

Arjmandi et al. (1997) showed that both ipriflavone (an isoflavone derivative) and soyabean containing isoflavones effectively prevented the unfavourable changes in serum and liver cholesterol levels associated with oestrogen loss. Studies in non-human primates (rhesus monkeys) also showed that phyto-oestrogen-intact soyabean had favourable effects on plasma lipid and lipoprotein concentrations, reducing LDL- and VLDL-cholesterol concentrations by $30-40 \%$ in both males and females, significantly increasing HDL-cholesterol concentrations for females $(15 \%)$ and significantly lowering total serum cholesterol:HDLcholesterol ( $20 \%$ for males, $50 \%$ for females), one of the most sensitive and discriminating markers of lipid-mediated CHD risk (Anthony et al. 1996).

Whilst such observations suggest that phyto-oestrogens, like oestrogens, can influence HDL-cholesterol and LDLcholesterol, the underlying mechanism and atherogenic potential of these changes is unknown. In the meta-analysis of soyabean-protein trials Anderson et al. (1995) suggested that the isoflavone content of soyabean may account for up to $60 \%$ of the hypocholesterolaemic effect. This has recently been disputed (Sirtori et al. 1997), since cholesterol-lowering effects have been observed in clinical studies where soyabean foods low in phyto-oestrogen content have been fed. The beneficial effects on lipid profiles may be only one factor in a series of oestrogenrelated protective responses. Honore et al. (1997) showed that phyto-oestrogens, like steroidal oestrogens, can enhance coronary vascular reactivity in atherosclerotic rhesus monkeys. The direct effects of oestrogens on endothelial cells and angiogenesis are an additional focus of interest (Fotsis et al. 1993; Jaggers et al. 1996), partly because angiogenesis in vascular walls occurs most commonly in atheromas and adherent thrombi. Fotsis et al. (1993) reported that the urine of healthy human subjects consuming a soyabean-based vegetarian diet contained inhibitors of endothelial cell proliferation, and identified genistein (one of the isoflavone precursors) as the effective compound. In vitro, this isoflavone precursor has been shown to inhibit endothelial cell proliferation, migration and tube formation as well as thrombin formation and platelet activation (Sargeant et al. 1993; Wilcox \& Blumenthal, 1995); the other phyto-oestrogens (daidzein, equol and enterolactone) were considerably less potent in these effects. If genistein can exert these same effects in vivo, it may slow the development or progression of atherosclerotic disease. 
There is great interest in the role of flavonoid-rich diets in reducing cardiovascular disease. However, the relative importance of the phyto-oestrogen components of such diets is still unclear. It has been suggested that some of the protective effects of oestrogens and Tamoxifen in terms of cardiovascular disease and cancer reflect their antioxidant properties and effects on membrane fluidity. Recent work by RuizLarrea et al. (1997) showed that genistein enhanced the resistance of LDL to oxidation in vitro, and was the most potent isoflavone antioxidant.

\section{Summary}

The biological mechanisms by which oestrogens and phytooestrogens may confer cardioprotection are multifactorial, acting through serum lipoproteins, haemostasis and vascular function. Whilst the evidence to show that exogenous oestrogen therapy may exert beneficial effects on biochemical markers of CHD risk is very compelling, the effects of HRT and other drug therapies, e.g. Raloxifene, on clinical outcome are unknown because of the lack of large-scale randomized placebo-controlled clinical trials. However, the long-term pursuit of therapeutic strategies to reduce CHD risk in the free-living population may be inappropriate, given the proven metabolic potential of phyto-oestrogens. If these compounds can mimic the effect of HRT, and if even some of their effects in vitro occur in vivo, then these compounds offer a serious alternative and rational approach to the primary prevention of CHD.

\section{References}

Anderson JW, Johnstone BM \& Cook-Newell ME (1995) Metaanalysis of the effects of soy protein intake on serum lipids. New England Joumal of Medicine 333, 272-286.

Anthony MS, Clarkson TB, Hughes CL Jr, Morgan TM \& Burke GL (1996) Soybean isoflavones improve cardiovascular risk factors without affecting the reproductive system of peripubertal rhesus monkeys. Journal of Nutrition 126, 43-50.

Arjmandi BH, Khan DA, Juma SS \& Svanborg A (1997) The ovarian hormone deficiency induced hypercholesterolemia is reversed by soy protein and the synthetic isoflavone, ipriflavone. Nutrition Research 17, 885-894.

Austin MA (1988) Epidemiologic associations between hypertriglyceridemia and coronary heart disease. Seminars in Thrombosis and Hemostasis 14, 137-142.

Baird DD, Umbach DM, Lansdell L, Hughes CL, Setchell KDR, Weinberg CR, Haney AF, Wilcox AJ \& McLachlan JA (1995) Dietary intervention study to assess estrogenicity of dietary soy among postmenopausal women. Journal of Clinical Endocrinology and Metabolism 80, 1685-1690.

Barrett-Connor E (1991) Postmenopausal women and prevention bias. Annals of Internal Medicine 115, 455-456.

Beresford SAA, Weiss NS, Voigt LF \& McKnight B (1997) Risk of endometrial cancer in relation to use of oestrogen combined with cyclic progestagen therapy in postmenopausal women. Lancet 349, 458-461.

Bergmann S, Siegert G, Wahrburg U, Schulte H, Assmann G \& Jaross W (1997) Influence of menopause and lifestyle factors on high density lipoproteins in middle-aged women. Menopause 4, $52-61$.
Bruschi F, Meschia M, Soma M, Perotti D, Paoletti R \& Crosignani PG (1996) Lipoprotein (a) and other lipids after oophorectomy and estrogen replacement therapy. Obstetrics and Gynaecology 88, 950-954.

Campos H, McNamara JR, Wilson PW, Ordovas JM \& Schaefer EJ (1988) Differences in low density lipoprotein subfractions and apolipoproteins in premenopausal and postmenopausal women. Journal of Clinical Endocrinology and Metabolism 67, 30-35.

Carroll KK (1991) Review of clinical studies on cholesterol lowering responses to soy protein. Journal of the American Dietetic Association 91, 8320-8327.

Cassidy A (1997) Risks and benefits of phytoestrogen-rich diets. In Hormonally Active Agents in Food, pp. 91-117 [G Eisenbrand, H Daniel, AD Dayan, PS Elias, W Grunow, FH Kemper, E Loser, M Metzler and J Schlatter, editors]. Weinheim, Germany: Wiley-VCH.

Cassidy A, Bingham S \& Setchell K (1994) Biological effects of isoflavones present in soy in premenopausal women: Implications for the prevention of breast cancer. American Journal of Clinical Nutrition 60, 333-340.

Cassidy A, Bingham S \& Setchell K (1995) Biological effects of isoflavones in young women: importance of the chemical composition of soyabean products. British Journal of Nutrition 74, 587-601.

Cassidy A, Faughnan M, Hughes R, Cathcart A, Fraser C, Setchell K \& Bingham S (1998) Hormonal effects of phytoestrogens in postmenopausal women and elderly men. American Journal of Clinical Nutrition (In the Press).

Castelli WP (1986) The triglyceride issue: a view from Framingham. American Heart Journal 112, 432-437.

Cohn JS, McNamara JR, Cohn SD, Ordovas JM \& Schaefer EJ (1988) Postprandial plasma lipoprotein changes in human subjects of different ages. Journal of Lipid Research 29, 469479.

Col NF, Eckman MH, Karas RH, Pauker SG, Goldberg RJ, Ross EM, Orr RK \& Wong JB (1997) Patient-specific decisions about HRT in postmenopausal women. Journal of the American Medical Association 277, 1140-1147.

Colditz GA, Hankinson SE, Hunter DJ, Willett WC, Manson JE \& Stampfer MJ (1995) The use of estrogens and progestins and the risk of breast cancer in postmenopausal women. New England Journal of Medicine 332, 1589-1593.

Farhat MY, Lavigne MC \& Ramwell PW (1996) The vascular protective effects of estrogen. FASEB Journal 10, 615-624.

Fotsis T, Peper M, Adlercreutz H, Fleischmann G, Hase T, Montesano R \& Schweigerer L (1993) Genistein, a dietary derived inhibitor of angiogenesis. Proceedings of the National Academy of Sciences USA 90, 2690-2694.

Gaziano JM, Manson JE, Branch LG, Colditz GA, Willett WC \& Buring JE (1995) A prospective study of consumption of carotenoids in fruits and vegetables and decreased cardiovascular mortality in the elderly. Annals of Epidemiology 5, 255-260.

Gerhard M \& Ganz P (1995) How do we explain the clinical benefits of oestrogen? Circulation $92,5-8$.

Griffin BA (1999) Lipoprotein atherogenicity: an overview of current mechanisms. Proceedings of the Nutrition Society 58, 163-169.

Gooderham MJ, Adlercreutz HA, Ojala ST, Wahala K \& Holub BJ (1996) A soy protein isolate rich in genistein and daidzein and its effects on plasma isoflavone concentrations, platelet aggregation, blood lipids and fatty acid composition of plasma phospholipids in normal men. Journal of Nutrition 126, 20002006.

Grodstein F, Stampfer MJ, Manson JE, Colditz GA, Willett WC, Rosner B, Speizer FE \& Hennekens CH (1996) Postmenopausal 
estrogen and progestin use and the risk of cardiovascular disease. New England Journal of Medicine 335, 453-461.

Hertog MGL, Feskens EJM, Hollman PCH, Katan MB \& Kromhout D (1993) Dietary antioxidant flavonoids and risk of coronary heart disease: the Zutphen Elderly Study. Lancet $\mathbf{3 4 2}$, $1007-1111$.

Hodgson JM, Puddey IB, Beilin LJ, Mori TA \& Croft KD (1998) Supplementation with isoflavonoid phytoestrogens does not alter serum lipid concentrations: a randomized controlled trial in humans. Joumal of Nutrition 128, 728-732.

Hokanson J \& Austin MA (1996) Plasma triglyceride level is a risk factor for cardiovascular disease independent of HDL cholesterol: a meta-analysis of population-based prospective studies. Journal of Cardiovascular Risk 3, 213-219.

Honore EK, Williams JK, Anthony MS \& Clarkson TB (1997) Soy isoflavones enhance coronary vascular reactivity in atherosclerotic female macaques. Fertility and Sterility 67, 148-154.

Iafrati MD, Karas RH, Aronovitz M, Kim S, Sullivan TR, Lubahn DB, O'Donnell TF, Korach KS \& Mendelsohn ME (1997) Estrogen inhibits the vascular injury response in estrogen receptor $\alpha$-deficient mice. Nature Medicine 3, 545-548.

Isles CG, Hole DJ, Hawthorne VM \& Lever AF (1992) Relation between coronary risk and coronary mortality in women of the Renfrew and Paisley survey: comparison with men. Lancet 339, 702-706.

Jaggers DC, Collins WP \& Milligan SR (1996) Potent inhibitory effects of steroids in an in vitro model of angiogenesis. Journal of Endocrinology 150, 457-464.

Key TJA, Thorogood M, Appleby PN \& Burr ML (1996) Dietary habits and mortality in 11000 vegetarians and health conscious people: results of a 17 year follow up. British Medical Journal 313, 775-779.

Kim-Schulze S, McGrowan A, Hubchak SC, Cid MC, Martin MB, Kleinman HK, Greene GL \& Schnaper HW (1996) Expression of an estrogen receptor by human coronary artery and umbilical vein endothelial cells. Circulation 94, 1402-1407.

Knopp RH (1991) Estrogen replacement therapy for reduction of cardiovascular risk in women. Current Opinion in Lipidology 2 , 240-247.

Kuiper GGJM, Carlsson B, Grandien K, Enmark E, Haggblad J, Nilsson S \& Gustaffson JA (1997) Comparison of the ligand binding specificity and transcript tissue distribution of estrogen receptors alpha and beta. Endocrinology 138, 863-870.

Kuiper GGJM, Enmark E, Peltohuikki M, Nilsson S \& Gustaffson JA (1996) Cloning of a novel estrogen receptor expressed in rat prostate and ovary. Proceedings of the National Academy of Sciences USA 93, 5925-5930.

Kuller LH, Gutai JP, Meilahn E, Matthewa KA \& Plantinga P (1990) Relationship of endogenous sex steroid hormones to lipids and apoproteins in postmenopausal women. Atherosclerosis 10, 1058-1066.

Lock M, Kaupfer P \& Gilbert P (1988) Cultural construction of the menopause syndrome: the Japanese case. Maturitas 10, 317 322.

Losordo DW, Kearney M, Kim EA, Jekanowski J \& Isner JM (1994) Variable expression of the estrogen receptor in normal and atherosclerotic coronary arteries in premenopausal women. Circulation 89, 1501-1510.

McDonald \& Stewart HJ (1991) Fatal myocardial infarction in the Scottish adjuvant tamoxifen trial. British Medical Journal 303, 435-437.

Magness RR \& Rosenfield CR (1989) Local and systemic oestradiol 17B: effects on uterine and systemic vasodilation. American Journal of Physiology 256, E536-E542.

Matthews KA, Meilahn E, Kuller LH, Kelsey SF, Caggiula AW \& Wing RR (1989) Menopause and risk factors for coronary heart disease. New England Journal of Medicine 321, 641-646.
Meade TW \& Berra A (1992) Hormone replacement therapy and cardiovascular disease. British Medical Bulletin 48, 276-308.

Meilahn EN, Kuller LH, Kiss JE, Mathews KA \& Lewis JH (1990) Change in coagulation parameters over one year in postmenopausal women. Circulation 84, 718 .

Murkies AL, Lombard C, Strauss BJG, Wilcox G, Burger HG \& Morton MS (1995) Dietary flour supplementation decreases postmenopausal hot flushes - effect of soy and wheat. Maturitas 21, 189-195.

Nagata C, Takatsuka N, Kurisu Y \& Shimizu H (1998) Decreased serum total cholesterol concentration is associated with high intakes of soy products in Japanese men and women. Journal of Nutrition 128, 209-213.

Nestel PJ, Yamashita T, Sasahara T, Pomeroy S, Dart A, Komesaroff P, Owen A \& Abbey M (1997) Soy isoflavones improve systemic arterial compliance but not plasma lipids in menopausal and perimenopausal women. Arteriosclerosis, Thrombosis and Vascular Biology 17, 3392-3398.

Pandey DK, Shekelle R, Selwyn BJ, Tangney C \& Stamler J (1995) Dietary vitamin $C$ and $\beta$-carotene and risk of death in middleaged men. The Western Electric study. American Journal of Epidemiology 142, 1269-1278.

RuizLarrea MB, Mohan AR, Paganga G, Miller NJ, Bolwell GP \& Rice-Evans CA (1997) Antioxidant activity of phytoestrogenic isoflavones. Free Radical Research 26, 63-70.

Sargeant P, Farndale RW \& Sage SO (1993) The tyrosine kinase inhibitors methyl 2,5-dihydroxycinnimate and genistein reduce thrombin-evoked tyrosine phosphorylation and $\mathrm{Ca}^{2}+$ entry in human platelets. FEBS Letters 315, 242-246.

Setchell KDR \& Adlercreutz H (1988) Mammalian lignans and phyto-oestrogens. Recent studies on their formation, metabolism and biological role in health and disease. In Role of the Gut Flora in Toxicity and Cancer, pp. 315-345 [IR Rowland, editor]. London: Academic Press.

Setchell KDR, Borriello SP, Hulme P, Kirk DN \& Axelson M (1984) Non-steroidal oestrogens of dietary origin: possible roles in hormone dependent disease. American Journal of Clinical Nutrition 40, 569-578.

Shewmon DA, Stock JL, Rosen CJ, Heinluoma KM, Hogue MM, Morrision A, Doyle EM, Ukena T, Weale V \& Baker S (1994) Tamoxifen and oestrogen lower circulating lipoprotein (a) concentrations in healthy postmenopausal women. Arteriosclerosis and Thrombosis 14, 1586-1593.

Shutt DA \& Cox RI (1972) Steroid and phytoestrogen binding to sheep uterine receptors in vitro. Journal of Endocrinology $\mathbf{5 2}$, 299-310.

Sirtori CR, Even R \& Lovati MR (1993) Soyabean diet and plasma cholesterol: From therapy to molecular mechanisms. Annals of the New York Academy of Sciences 676, 188-201.

Sirtori CR, Gianazza E, Manzoni C, Lovati MR \& Murphy PA (1997) Role of isoflavones in the cholesterol reduction by soy protein in the clinic. American Journal of Clinical Nutrition $\mathbf{6 5}$, 166-171.

Soma MR, Baetta R \& Crosignani PG (1997) The menopause and lipid metabolism: strategies for cardiovascular disease prevention. Current Opinion in Lipidology 8, 229-235.

Stampfer MJ \& Colditz GA (1991) Estrogen replacement therapy and coronary heart disease: a quantitative assessment of the epidemiologic evidence. Preventive Medicine 20, 47-63.

Stampfer MJ, Colditz GA, Willett WC, Manson JE, Rosner B, Speizer FE \& Hennekens CH (1991) Postmenopausal estrogen therapy and cardiovascular disease - 10 year follow-up from the nurses health study. New England Journal of Medicine 325, 756762.

Stefanick ML, Legault C, Tracy RP, Howard G, Kessler CM, Lucas DL \& Bush TL (1995) Distribution and correlates of plasma fibrinogen in middle-aged women. Initial findings of the 
Postmenopausal Estrogen/Progestin Interventions (PEPI) study. Arteriosclerosis, Thrombosis and Vascular Biology 15, 20852093.

Stevenson JC, Crook D \& Godsland IF (1993) Effects of age and menopause on lipid metabolism in healthy women. Arteriosclerosis $\mathbf{9 8 , 8 3 - 9 0}$

Sullivan TR Jr, Karas RH, Aronovitz M, Faller GT, Ziar JP, Smith JJ, O'Donnell TF Jr \& Mendelsohn ME (1995) Estrogen inhibits the response-to-injury in a mouse carotid artery model. Journal of Clinical Investigation 96, 2482-2488.

Walsh BW, Kuller LH, Wild RA, Paul S, Farmer M, Lawrence JB, Shah AS \& Anderson PW (1998) Effects of Raloxifene on serum lipids and coagulation factors in healthy postmenopausal women. Journal of the American Medical Association 279 1445-1451.

Wilcox G, Wahlqvist ML, Burger HG \& Medley G (1990) Oestrogen effects of plant derived foods in postmenopausal women. British Medical Journal 301, 905-906.

Wilcox JN \& Blumenthal BF (1995) Thrombotic mechanisms in atherosclerosis: Potential impact of soy protein. Journal of Nutrition 125, 631s-638s.

Williams CM (1997) Cardiovascular risk factors in women. Proceedings of the Nutrition Society 56, 383-391.

Williams JK, Adams MR, Herrington DM \& Clarkson TB (1992) Short term administration of estrogen and vascular responses of atherosclerotic coronary arteries. Journal of the American College of Cardiology 20, 452-457. 